\title{
Patios escolares y diversidad sociocultural en Cataluña. Una investigación sobre usos y posibilidades para el juego y el aprendizaje
}

\author{
Cris Molins-Pueyo
}

Universitat Autònoma de Barcelona. Departament d'Antropologia Social i Cultural

cris.molins@uab.cat

\section{Resumen}

El artículo presenta los resultados de una investigación realizada sobre una muestra de patios de treinta centros de educación primaria de Cataluña durante el curso 2007-2008 ${ }^{1}$, teniendo en cuenta la diversidad física, socioeconómica y educativa presentes en nuestro territorio, y llevada a cabo con el objetivo de identificar y analizar las conceptualizaciones de la comunidad educativa sobre los usos, los espacios, las actividades y los tiempos de patio escolar en los centros educativos. Este cuestionamiento indirecto surge a partir de resultados de investigaciones anteriores sobre la consideración del patio escolar como un espacio educativo, y los trabajos anteriores nos han permitido constatar las diferencias de uso del juego en la escuela según las etapas educativas estudiadas. Hemos constatado también el mal uso y los usos limitados del patio como espacio educativo, con poca profundización de las posibilidades que ofrece. Se han utilizado técnicas cuantitativas y cualitativas, teniendo en cuenta la diversidad presente en el territorio definida por las variables siguientes: población, titularidad de los centros educativos, diversidad sociocultural y económica y tamaño de los centros educativos. Por un lado, se ha procedido a aplicar un instrumento de encuesta al alumnado de cuarto de primaria y, por otro, se han realizado entrevistas a miembros de los equipos directivos de los centros y se ha aplicado un protocolo de observación de los patios escolares.

Palabras clave: antropología de la educación; juego infantil y juvenil; socialización; etnografía escolar.

1. Este artículo se presentó como comunicación en el VI Congreso de la Associació Catalana de Sociologia celebrado en la UAB en abril de 2009, en el Grupo 9, coordinado por el Dr. Fidel Molina. Se presentan los resultados de la investigación realizada por la autora durante el curso 2008-2009 por encargo de la International Play Association, IPA España, y financiada por la Fundació Jaume Bofill. 


\begin{abstract}
School playgrounds and socio-cultural diversity in Catalonia. A study on the uses and possibilities for playing and learning
\end{abstract}

In this paper we present the results of a study carried out on a sample of 30 primary school playgrounds in Catalonia. The fieldwork was conducted during one full school year (2007$2008)^{2}$. The central aim of the study was to identify the notions and ideas of members of the school community in relation to the spaces, activities and uses made of the schools' playgrounds. This approach draws on results from previous research that considers the school playground as an educational space. The purpose of this work has been to diagnose the situation of playgrounds in a diverse sample of primary schools in Barcelona in terms of both built facilities and socioeconomic and educational differences. Data were obtained using quantitative and qualitative methods including a survey, interviews and a complete playground observation protocol developed by the author. The study reveals important differences in game playing according to the educational stage analyzed. We find that the use of school playgrounds as an educational space is very limited, and that many educators have little knowledge about the possibilities playgrounds offer educators to meet the challenges they face and are concerned about.

Keywords: anthropology of education; children and youth play; socialization; school ethnography.
Sumario
1. Introducción
4. Resultados
2. Los patios escolares
5. Conclusiones e implicaciones
y sus usos educativos
Referencias bibliográficas
3. Objetivos y metodología

\title{
1. Introducción
}

El juego es un ensayo de la vida adulta más o menos consciente, es interacción con otras personas y exploración de las propias limitaciones, es explosión de energía más o menos medida, puede ser una actividad más o menos reglada o libre, más movida o sedentaria, pero, sobre todo, tiene que contar con el componente lúdico. Hay que distinguir el juego de los juegos, lo que en inglés se corresponde con los términos play y game. La primera acepción de juego (play) se refiere a esta orientación especial hacia los recursos de juego y se puede referir a varias clases de comportamiento lúdico, en contraposición a la segunda acepción de juego (game), que no es nada más que su ordenación en las actividades regladas e institucionalizadas. Por esta segunda acepción se entiende que hay una serie de reglas más o menos explícitas que hacen que los

2. This article was presented as a communication at the Sixth Congress of the Catalan Association of Sociology held at UAB in April 2009, in Group 9, coordinated by Dr. Fidel Molina. We present the results of research conducted by the author in 2008-2009, which was commissioned by the International Play Association, IPA Spain, and funded by the Fundació Jaume Bofill. 
juegos puedan ser comunicados, transmitidos, enseñados y aprendidos (Garvey, 1978). En este sentido, los juegos deportivos serían la máxima institucionalización de estas actividades lúdicas, en cuanto a que hace falta un cumplimiento exacto de las reglas, que estas son invariables y modificarlas significa jugar a otra cosa distinta.

En nuestro contexto sociocultural, una de las instituciones sobre las que recae más responsabilidad de transmisión de contenidos es la escuela, porque está pensada y organizada exclusivamente con este objetivo: convertir a los miembros más jóvenes de nuestro grupo en miembros de pleno derecho, en ciudadanos y ciudadanas con deberes y derechos. La organización de esta institución incorpora la presencia de un espacio específico de juego y recreo: el patio. A lo largo de la historia de la institución escolar, el patio ha sido pensado de varias maneras, ha sido más o menos regulado. Hoy en día, todos los centros educativos de las etapas obligatorias de formación de nuestro país disponen, teóricamente, de patio.

El tiempo dedicado en los centros educativos al recreo es de una media de treinta minutos al día en la etapa de educación primaria. Son muchas horas a lo largo del curso, de hecho, se trata de 525 horas, más que las dedicadas a materias como educación para la ciudadanía y los derechos humanos, educación física, religión (que es voluntaria) o lengua extranjera y casi con la misma carga horaria que lengua y literatura catalana o lengua y literatura castellana, o exactamente las mismas horas que se dedican a educación artística ${ }^{3}$. Entendemos, pues, que se convierte en un tiempo muy importante en la formación de los niños dentro del ámbito de la educación formal. Es por estos motivos que establecemos como centro de nuestro análisis aquellas cosas (actividades, prácticas, interacciones) que suceden en el patio escolar. Estudiamos qué características tienen y qué conceptualizaciones, percepciones y discursos construyen los sujetos agentes sobre estos usos y actividades.

El objetivo central de esta investigación es la de interrogarnos acerca tanto de las prácticas como de las conceptualizaciones de la comunidad educativa sobre los usos, los espacios, las actividades y los tiempos de patio escolar en centros educativos de Cataluña. Este cuestionamiento indirecto surge a partir de resultados de investigaciones anteriores sobre la consideración del patio escolar como un espacio educativo. Estos trabajos nos han permitido constatar las diferencias de uso del juego en la escuela según las etapas educativas estudiadas: mientras el juego es considerado una estrategia central en el proceso

3. Extraído del Decreto 142/2007, de 26 de junio, por el cual se establece la ordenación de las enseñanzas de la educación primaria. Anexo 3.

«Horarios globales. La asignación horaria global de las áreas de la educación primaria es la siguiente: Lengua y literatura catalana y castellana: 1.085 horas (lengua y literatura catalana 420 horas y lengua y literatura castellana 420 horas, estructuras lingüísticas comunes 245 horas), Lengua extranjera: 420 horas, Conocimiento del medio natural, social y cultural: 630 horas, Educación artística: 525 horas, Educación física: 385 horas, Matemáticas: 665 horas, Educación para la ciudadanía y los derechos humanos: 35 horas, Religión (voluntaria): 315 horas, Recreo: 525 horas». 
de enseñanza-aprendizaje en la etapa de educación infantil, en la etapa de educación primaria va perdiendo protagonismo, hasta prácticamente no ser considerado dentro del ámbito escolar en la etapa de educación secundaria (Molins, 2005). Hemos constatado también el mal uso y los usos limitados de los patios como espacio educativo, con poca profundización de las posibilidades de juego que ofrecen.

La propuesta de este trabajo ha sido diagnosticar la situación de los patios en una muestra de centros educativos de Cataluña que represente la diversidad física, socioeconómica y educativa presentes en nuestro territorio. Nos centraremos en la etapa de educación primaria, puesto que, como hemos dicho antes, hemos constatado la pérdida de valor que ha tenido el juego en el espacio escolar, aunque sea muy presente, en cambio, en el resto de ámbitos de la vida de los niños entre seis y doce años y tenga mucha importancia en el desarrollo de los chicos y las chicas.

A pesar de que la búsqueda en este ámbito temático aglutina intereses de varias disciplinas, no hay muchos precedentes emprendidos específicamente con el objetivo de diagnosticar la situación de los patios escolares, ni mostrar los usos y las valoraciones que tienen los diferentes agentes implicados en su uso. A continuación, revisamos los referentes más destacados en el ámbito internacional y nacional y qué producción se ha ido generando en la literatura de las publicaciones periódicas dedicadas a la divulgación educativa dirigida al profesorado en formación y en activo.

\section{Los patios escolares y sus usos educativos}

\subsection{Una breve revisión de la literatura internacional}

En el contexto internacional, la búsqueda se ubica principalmente en los países anglosajones, principalmente EE.UU., Reino Unido y Canadá, donde, desde los años sesenta y setenta, surgen estudios centrados en el análisis de la seguridad en los espacios de juego que incorporan tanto el estudio de parques infantiles como de patios escolares. Estos estudios han analizado los materiales empleados en la creación de los elementos de juego, pasando por la evaluación de los materiales de construcción de las superficies de los espacios y el análisis de los incidentes registrados en los hospitales. Con ello han sido los países pioneros en la elaboración de normativas, la creación de organismos y el nacimiento de instituciones que se dedican a velar por estos aspectos de seguridad (Howard et al., 2005; Barbour, 1999; Hudson et al., 2005; Meyerhoff, 2001). Estos autores avanzan en el ejercicio y en las técnicas para medir y observar los resultados del uso de los elementos físicos de los patios y parques infantiles, de forma que identifican los materiales empleados y la peligrosidad de los accidentes que suceden, correlacionando los materiales empleados, la valoración de los elementos de juego y el estado físico de los patios y los materiales, reconstruyendo como se generan los accidentes infantiles. Sus resultados, a pesar de informar del número y la gravedad de los accidentes en parques infantiles, 
plazas y algunos patios escolares, no nos dan información sobre los usos de los espacios de juego.

Encontramos algunos precedentes de investigación en el análisis de la percepción del profesorado y los espacios de juego en los centros educativos. Stratton (2000) analiza intervenciones sencillas llevadas a cabo desde áreas curriculares en los patios escolares y muestra como, por ejemplo, una pintada de líneas de juego con el objetivo de incrementar la actividad física del alumnado consigue el incremento de esta actividad física. Otras investigaciones se centran en el análisis de las actividades infantiles y la producción lingüística que implican estas actividades de los niños en los patios por parte de profesorado en formación. Grugeon (2005) señala cómo las observaciones en que intervengan varios agentes y la observación cuidadosa de los patios escolares aportan información muy útil desde el punto de vista educativo, para conseguir datos imposibles de ser analizados en otros contextos, tanto dentro como fuera de la escuela, que tienen grandes potencialidades para ser aprovechados en el contexto escolar.

Otras investigaciones se centran en el análisis específico de las actividades llevadas a cabo en los patios. Swain (2000), en EE.UU., y Blatchford et al. (2003), en el Reino Unido, analizan las diferencias en las actividades desarrolladas en los patios según el género y el origen étnico, y establecen que el género y la clase social son variables mucho más explicativas en cuanto a analizar las diferencias de actividades desarrolladas en los espacios de patio escolar y señalan como uno de los resultados de sus observaciones que el juego interétnico es fácil en el patio de juego e implica poca producción lingüística, a pesar de que ya resaltan que esta conclusión se contradice con resultados de otras investigaciones. Se cuestionan sobre la posibilidad que este hecho esté relacionado específicamente con los orígenes étnicos implicados en las observaciones, sin profundizar en este aspecto. Swain (2000) analiza diferencias de género en las actividades desarrolladas en los patios. Concluye que el predominio del fútbol en los patios es una forma de expresión de la hegemonía masculina y muestra cómo, a pesar de los intentos de algunas chicas de incorporarse a esta actividad, dichos intentos resultan infructuosos, dado que el papel de una parte del profesorado no hace nada más que perpetuar esta situación, porque no potencia los valores de la política de igualdad en la escuela en este ámbito. Revelan, básicamente, la centralidad de las variables de género y etnia y alientan a centrar nuestras miradas en los roles del profesorado en los patios.

En ese mismo sentido, Colwell y Lindsey (2005), por ejemplo, analizan los tipos de juego por género, mostrando las diferencias en las valoraciones hechas por unas y otras a través de la observación directa de las actividades del patio. Señalan que, a menudo, las actividades o los juegos realizados en el patio mezclan diferentes tipos de juegos y analizan específicamente la presencia de juego dramático en las diversas formas de entretenimiento de chicos y chicas. A pesar de que sus estudios han sido realizados en la etapa de educación infantil, lo que principalmente aportan a la investigación es la metodología empleada. Son los referentes de la aplicación de técnicas de investigación cualitativa en los patios. 


\subsection{Antecedentes de investigación en Cataluña sobre patios escolares, juego y socialización}

En nuestro país, disponemos de referentes importantes en la reflexión del significado del juego y de sus utilidades educativas, a pesar de que no disponemos de ellos en el campo de la investigación y la diagnosis del juego o de los espacios de juego en el ámbito escolar. Desde los trabajos de recopilación de juegos de Amades hasta nuestros días, son numerosos los ejemplos de recuperación y compilación de diversidad de tipos de juegos, de juegos tradicionales, de juegos del mundo, de juegos educativos, de juegos de interior y de juegos de exterior.

En los últimos años ha crecido el interés de la educación física por los juegos como herramienta didáctica, específicamente los juegos tradicionales, que permitirían a su vez recuperar contenidos populares de nuestra cultura e incrementar la actividad física del alumnado del país (Lavega, 2003 y 2006; Trigueros, 2000; Bantulà, 2003).

Los patios escolares han sido estudiados específicamente por Bonal y Tomé (1996), pioneros en nuestro país en el análisis de las diferencias de género en el uso de los espacios de juego escolar. Fundamentalmente, esta línea de búsqueda establece protocolos de observación cuidadosa de lo que sucede en los patios, y se diagnostican y se establecen criterios a tener en cuenta en las intervenciones a realizar en los patios para que estos dejen de contribuir a la discriminación de género dentro de la escuela (Rambla y Rovira, 1999).

Debe mencionarse específicamente el papel del Instituto Municipal de Educación del Ayuntamiento de Barcelona, que, con proyectos a largo plazo, como la convocatoria de ayudas a estudios desarrollados en centros educativos de la ciudad, el proyecto Barcelona Identidades ${ }^{4}$, financia y acompaña procesos de intervención en patios escolares, entre otros espacios. Se han desarrollado seminarios especializados en el análisis de los patios, entre otros, centrándose en valores como la convivencia, la autonomía o el respeto, hasta llegar a la última convocatoria, en que se centran específicamente en la transformación de estos espacios teniendo en cuenta los aspectos más ecológicos. Esto comporta, por ejemplo, la incorporación de espacios verdes en los patios, con su materialización en el libro Recuperamos los jardines escolares (2007), así como procesos de análisis emprendidos en los seminarios de las convocatorias Barcelona Identidades, en los que ya surgían propuestas de proyectos de transformación de patios escolares presentados por los propios equipos docentes de los centros.

\subsection{Algunas reflexiones desde la formación del profesorado}

Las publicaciones periódicas dirigidas al profesorado también constituyen un ámbito importante de análisis, dado que la difusión o divulgación educativa se convierte en un espacio de formación permanente y conviene que sea breve-

4. Para más información sobre las diferentes convocatorias y objetivos, consultar la siguiente página web: http://www.bcn.es/imeb/bcnidentitats/catala/convocatories.htm. 
mente analizado para ver las tendencias, las conceptualizaciones y los modelos de intervención que les llegan. Después de revisar la literatura de los últimos diez años en las principales revistas de educación del país (Guix, Aula, Infancia y Cuadernos de Pedagogía), los artículos analizados nos ofrecen un panorama centrado en la presentación de experiencias, puntuales y aisladas, llevadas a cabo en patios escolares de centros principalmente ubicados en la etapa de educación infantil, con menor frecuencia en la de primaria y prácticamente inexistentes en relación con la etapa de educación secundaria.

Desde el punto de vista temático, muchas de estas experiencias o propuestas de actividades presentadas se vinculan a la implantación de huertos escolares (sobre todo en los últimos cinco años) y a llevar a cabo experiencias directamente vinculadas con áreas curriculares como educación física, matemáticas, ciencias sociales y educación plástica y artística. El número más alto de experiencias se encuentra en el área curricular de educación física (Castro, 2008), como se muestra en el monográfico número 10 de la revista Tándem: Didáctica de la Educación Física. Las otras áreas que aparecen con más frecuencia son la de matemáticas (Monterde, 2006), que realiza un ejercicio de geometría a partir de la medida del patio escolar o las experiencias y los recursos presentados para enseñar matemáticas a partir de juegos (Callís, 2003; Deulofeu, 2003), juegos y actividades de cálculo (Edo, 2003), o el área de ciencias naturales, con la presentación de experiencias de observación de los pájaros del patio (Chivite, 2002), en que también se realizan algunas intervenciones como, por ejemplo, la de elaborar y colgar casetas nido para los pájaros.

La otra área que a menudo aparece es la de ciencias sociales. Destaca un monográfico de la revista Íber (número 30) que reúne una compilación de artículos que reflexionan sobre la incorporación de juegos de simulación para la enseñanza-aprendizaje de las ciencias sociales, en general, y la geografía, en particular.

Se documentan algunos ejemplos en que participan varias áreas curriculares en algunas intervenciones educativas en el patio incorporando la recuperación de juegos de los abuelos y las abuelas (Bernabé, 2006), en que hay participación del área de lengua, plástica y educación física o la experiencia presentada por Rodríguez (2003), en la cual también participan varias áreas en su ejecución y en la cual se incorporan las familias del alumnado en la recuperación de juegos tradicionales. En una experiencia llevada a cabo en la etapa de infantil, también se plantea la intervención en el patio pintando un mural de uno de los artistas trabajados dentro del aula (Salaverría et al., 2003), en que también participan otras áreas como la de lengua.

En una revisión de los números de los últimos diez años, tan sólo hemos encontrado documentados un par de casos en que se proponen intervenciones en centros educativos de primaria para ser transformados. En uno se propone la disminución y la prevención de la violencia escolar (Pereira et al., 2002) por medio de un proceso de identificación de las necesidades del centro, responsabilizándolo del desarrollo de los cambios y estableciendo el plan de intervención. En el segundo caso, se documenta el proceso de transformación seguido por un CEIP de Barcelona (Agramunt et al., 2004), en el cual se centran en la 
participación del alumnado en todo el proceso desarrollado a partir de las asambleas de clase. Se elaboran cuestionarios para detectar las carencias y se realizan intervenciones de diferentes tipos: poner un banco y una fuente, adaptar una azotea "para juego tranquilo», pintar, incorporar patines, etc., y se evalúan los cambios a partir de las valoraciones del mismo alumnado.

No hemos encontrado ninguna referencia, en cambio, a trabajos de diagnosis de patios en una muestra de centros según su diversidad, ni el análisis de cuáles son los elementos presentes en los patios, cómo se distribuyen los tiempos y los espacios, qué usos hace el alumnado de ellos, cómo se agrupa, cómo se relaciona o cuál es el papel que tiene el profesorado.

\section{Objetivos y metodología}

En una primera fase, este estudio persiguió dos objetivos:

- Diagnosis. Profundizar en el conocimiento de las condiciones generales y del estado físico de los patios a través de un mapa de situación de los patios escolares en los centros educativos del área metropolitana de Barcelona.

- Evaluación. Analizar la situación de los patios de juegos en las escuelas y las conceptualizaciones que tienen las personas implicadas en los procesos de enseñanza-aprendizaje sobre los mismos.

\subsection{Muestra}

Para obtener la información, se han empleado técnicas cuantitativas y cualitativas en una muestra de treinta escuelas de Barcelona, teniendo en cuenta la diversidad presente en el territorio definida por las variables siguientes: población, titularidad de los centros educativos, diversidad sociocultural y económica y tamaño de los centros educativos. Por un lado, se ha procedido a aplicar un instrumento de encuesta al alumnado de cuarto de primaria y, por otro, se han realizado entrevistas y se ha aplicado un protocolo de observación de los patios (desarrollado en Molins, 1998).

La muestra se ha confeccionado a partir de una serie de variables independientes que determinan diferencias en los resultados obtenidos en los patios y, por lo tanto, nos ayudan en la selección de los centros educativos que conformaron la muestra de conveniencia buscando la máxima variabilidad posible de la diversidad de situaciones con que nos encontramos.

Las variables consideradas en la selección de los centros educativos de la muestra son:

- Entorno sociocultural. Se ha establecido la presencia de varios grupos sociales y culturales en el entorno más inmediato del centro, la accesibilidad a recursos económicos de la población atendida, la marginalidad, la pertenencia a élites y la pertenencia a un grupo cultural minoritario o no. Nos hemos centrado en el ámbito urbano, básicamente en la Región Metropo- 
litana de Barcelona, ya que acoge el 70\% de la población escolarizada de Cataluña.

- Clase social. Hemos pedido a la Administración que caracterice a los centros según la situación socioeconómica de la población escolar mayoritaria que atiende. En este caso, las clasificaciones sobre clases sociales siempre son controvertidas y un análisis más profundo de la población escolarizada nos daría variaciones internas, seguramente más importantes en el caso de la clase media, puesto que la amplitud de esta categoría es grande. Justo es decir que, habiendo pedido al alumnado que nos referenciara el trabajo del padre y de la madre ${ }^{5}$, hemos usado el trabajo del padre para cruzarlo con la categorización de clase social, y la distribución de las respuestas referidas a estudios superiores y autónomos perfila la misma lógica que la de la clase social otorgada. En este caso, la distribución de centros es de diez por cada una de las tres clases diferenciadas.

- Presencia de inmigración. La demanda hecha a la Administración ha sido la de identificar aquellos centros educativos que acogen a más población de origen inmigrando que el resto de centros del entorno inmediato. Hemos comprobado esta información cruzándola con los datos de los cuestionarios pasados al alumnado de cuarto y hemos establecido una relación significativa entre las variables de clase social y titularidad de los centros educativos y la presencia de inmigración en los hogares de estos chicos y chicas, pero en esta información profundizaremos más adelante. Para esta última variable, la distribución de los centros queda en catorce con inmigración y dieciséis con muy poca inmigración en relación con el resto de centros del entorno más cercano.

- Género. Nos interesa analizar las informaciones obtenidas a raíz de identificar las similitudes y diferencias de comportamientos, respuestas y valoraciones de los chicos y las chicas observados. En la selección de centros, se contempla la presencia de dos de ellos que segregan al alumnado por sexos, a pesar de que se trata de una práctica minoritaria en los centros educativos del territorio catalán. Se trata de dos centros de titularidad privada concertada. Una de estas escuelas atiende exclusivamente a niñas, y la otra, a niños.

- Titularidad del centro educativo. Nos interesa contemplar la variabilidad de situaciones administrativas de los centros educativos en nuestro territorio, para ello hemos seleccionado centros de titularidad pública y centros de titularidad privada. La gran mayoría de estos últimos han sido centros concertados, es decir, que están financiados con fondos públicos, y hemos seleccionado un centro de titularidad privada no concertado. A pesar de

5. Justo es decir que el nivel de respuesta ha sido de un $85 \%$, tanto en el caso del padre como de la madre. El problema ha sido la codificación de las respuestas, que, teniendo en cuenta la edad de las personas encuestadas y la propia controversia del concepto de clase social, nos resultan poco precisas. Finalmente, hemos optado por codificar aquellos casos en que la necesidad de estudios superiores es clara y directamente han contemplado que fueran autónomos, sin saber el nivel de estudios y dejar una gran categoría por los trabajos con baja calificación, en cuanto que no sabíamos del todo el lugar ocupado o el trabajo desarrollado. 
Tabla 1. Características de los centros de la muestra

\begin{tabular}{|c|c|c|c|c|}
\hline & \multicolumn{4}{|c|}{ Clase alta } \\
\hline & \multicolumn{2}{|c|}{ Público } & \multicolumn{2}{|c|}{ Concertado } \\
\hline & Grande & Pequeño & Grande & Pequeño \\
\hline No inmigrante & 12 & 13 & $14-15-16$ & 17 \\
\hline \multirow[t]{4}{*}{ Sí inmigrante } & 7 & 5 & 18 & 19 \\
\hline & \multicolumn{4}{|c|}{ Clase media } \\
\hline & \multicolumn{2}{|c|}{ Público } & \multicolumn{2}{|c|}{ Concertado } \\
\hline & Grande & Pequeño & Grande & Pequeño \\
\hline No inmigrante & $11-20$ & $3-6$ & 21 & 22 \\
\hline \multirow[t]{4}{*}{ Sí inmigrante } & 9 & 2 & 31 & 23 \\
\hline & \multicolumn{4}{|c|}{ Clase baja } \\
\hline & \multicolumn{2}{|c|}{ Público } & \multicolumn{2}{|c|}{ Concertado } \\
\hline & Grande & Pequeño & Grande & Pequeño \\
\hline No inmigrante & 4 & 25 & 29 & 27 \\
\hline Sí inmigrante & 8 & $10-28$ & 26 & $1-30$ \\
\hline
\end{tabular}

La ubicación de los centros en cada categoría se realiza a partir de los datos facilitados por el Departamento de Educación.

El centro número 16 es de titularidad privada no concertada.

Los nombres de las casillas se corresponden con el código de centro educativo asignado a cada escuela.

Fuente: Elaboración propia

que no estaba previsto en el diseño original y que se trata de una oferta minoritaria en Cataluña, también existe y recibe aportaciones económicas públicas desde la Administración local en concepto de mantenimiento del centro. Los centros quedan distribuidos en la mitad por cada categoría.

- Tamaño del centro educativo. Nos interesa caracterizar los centros por tamaño y número de alumnado, dado que entendemos que la competencia por el espacio educativo podría determinar la organización y la intervención en los patios escolares. Teniendo en cuenta las características de los centros educativos por su titularidad, esta variable ha sido considerada con valores diferentes según si los centros son públicos o privados, esto es, los centros pequeños públicos son los de una línea y los grandes los de dos o más. En cuanto a los centros concertados, los pequeños son los de una y dos líneas, y los grandes, los de tres líneas o más. Se ha considerado el hecho de que las ratios en los centros concertados son superiores a las de los públicos, así que, según datos del Departamento de Educación, la ratio de unidad de alumnos para primaria es de 21 para los centros públicos y 24,3 para los privados $^{6}$. También tenemos la mitad de la muestra en cada categoría.

- Etapa educativa. Nos hemos centrado en la etapa de primaria por varios motivos, empezando por el hecho de que en nuestro sistema educativo es

6. Fuente: Estadísticas del Departamento de Educación de la Generalitat de Cataluña. http:// www.gencat.net.

En el curso 2006-2007, constan 244.372 alumnos de primaria en centros públicos y 11.574 unidades. En el caso de los centros privados, son 145.506 alumnos por 5.975 unidades. 
la más larga y la única totalmente obligatoria. Hemos constatado, a partir de otras búsquedas, que es en esta etapa que el patio y el juego empiezan a perder la importancia central a nivel pedagógico y global que se le otorga en la etapa precedente, a la vez que hemos observado limitaciones en los usos del patio como espacio educativo. Es decir, hemos constatado el desperdicio de su potencial en relación precisamente con los objetivos educativos que se propone la etapa (Molins, 2005). Hemos seleccionado el curso de cuarto de primaria en la priorización de las observaciones etnográficas, dado que el alumnado se encuentra en un momento de transición madurativa en la cual todavía se detectan muchas prácticas lúdicas inequívocamente infantiles, pero ya empiezan a aparecer otras que están más asociadas a la adolescencia.

\subsection{Instrumentos}

\section{Observaciones en el patio}

Se han realizado observaciones de momentos de recreo, en los que se han descrito los espacios de patio y los ambientes generales de lo que allí sucede. Así mismo, se han focalizado las observaciones y se han concentrado las miradas entre una y tres observaciones de actividades concretas, analizando la génesis y el desarrollo de la actividad, los roles llevados a cabo, los participantes, el tipo de actividad y la finalización de la misma. En total tenemos sesenta y ocho observaciones focalizadas.

\section{Entrevistas al equipo directivo}

Se han hecho entrevistas semiestructuradas a los miembros de los equipos directivos de cada uno de los centros educativos. Hemos obtenido, por lo tanto, treinta entrevistas realizadas a coordinadores y coordinadoras pedagógicos, directores y directoras. Se les ha interrogado sobre la presencia del patio, el recreo y el juego en el proyecto educativo del centro y cómo se recoge en diferentes documentos el PEC, el RRI, el PA, qué usos lectivos y extraescolares se hace, así como sobre el acceso a los materiales, las prohibiciones y la existencia de proyectos y comisiones de patio.

\section{Encuestas al alumnado}

Se ha aplicado una encuesta al alumnado de un grupo clase de cuarto de primaria de cada centro educativo (703 cuestionarios). La combinación de variables independientes nos permite obtener la siguiente distribución de las encuestas contestadas:

- Por clase social: baja: 32\%, media: $34 \%$ y alta: $34 \%$.

- Por tamaño del centro: pequeño: $47 \%$ y grande: $53 \%$.

- Por titularidad del centro: pública: $48 \%$ y privada: $52 \%$.

- Por presencia de inmigración: presencia: $45 \%$ y no presencia: $55 \%$.

- Por género: un $49 \%$ son chicas y un $51 \%$ son chicos.

— Por edad: el 93\% nació en 1998 y un 6\%, en 1997. 
Estas tres fases de obtención de datos y los diferentes instrumentos aplicados nos permiten obtener y reconstruir información triangulada sobre los ejes que se representan en este gráfico:

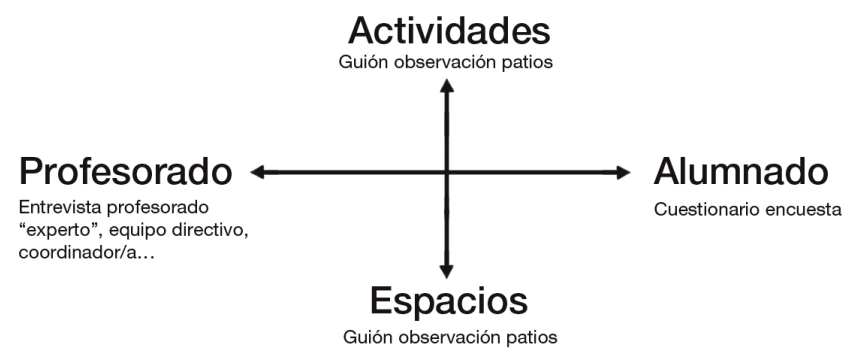

La recogida de datos se realizó entre los meses de septiembre de 2007 y enero de 2008. El diseño se inició a principios del año 2007, con el diseño de los instrumentos y el cierre de la propuesta de proyecto. El análisis de los datos se inició en febrero de 2008 hasta el mes de junio, en que se finalizó la redacción del informe.

El equipo estaba formado por cinco investigadores que participaron exclusivamente en el trabajo de campo y dos personas que colaboraron en el trabajo de campo, combinándolo con tareas de coordinación.

Se estableció un primer periodo de formación, una sesión de trabajo de presentación de los instrumentos y las primeras visitas al campo se realizaban en parejas rotativas, para contrastar las observaciones. A partir de aquel momento, el trabajo de campo se realizó individualmente, pero en coordinación sistemática con la responsable de esta fase de la investigación.

Las tareas del equipo y de los centros se repartieron como se muestra a continuación:

\begin{tabular}{ll}
\hline Tareas del equipo de investigación & Tareas del centro educativo \\
\hline $\begin{array}{l}\text { Entrevista con un miembro del equipo } \\
\text { directivo del centro. }\end{array}$ & $\begin{array}{l}\text { Asignar una persona del equipo directivo } \\
\text { del centro como enlace de contacto con } \\
\text { la asociación IPA, España. } \\
\text { Procurar una entrevista entre la persona } \\
\text { de contacto y los investigadores. }\end{array}$ \\
$\begin{array}{ll}\text { Recogida de datos relativos a la } \\
\text { morfología y a la estructura del patio. }\end{array}$ & $\begin{array}{l}\text { Permitir la recogida de datos del patio sin la } \\
\text { presencia del alumnado (planos, fotografías, } \\
\text { croquis, etc.). }\end{array}$ \\
$\begin{array}{ll}\text { Observaciones en los patios de las } \\
\text { escuelas durante el tiempo de recreo de } \\
\text { los grupos de segundo ciclo de primaria. }\end{array}$ & $\begin{array}{l}\text { Permitir el acceso al patio de dos o tres } \\
\text { persones del equipo de investigación durante } \\
\text { el te primaria, en tres momentos y días distintos. }\end{array}$ \\
$\begin{array}{ll}\text { Cuestionario de encuesta pasado a un } \\
\text { curso de alumnos de cuarto de primaria. }\end{array}$ & $\begin{array}{l}\text { Facilitar el acceso de una persona del equipo } \\
\text { de investigación a una clase de cuarto de } \\
\text { primaria para pasar una encuesta colectiva } \\
\text { a los alumnos de este grupo. }\end{array}$ \\
\hline
\end{tabular}


Resumen de la secuencia seguida en el trabajo de campo:

1. Contacto con el centro desde la coordinación del trabajo de campo. Presentación de los objetivos del proyecto y facilitación de documentación relativa:

- Documento de presentación del estudio.

- Documento informativo sobre IPA España.

2. Contacto con el investigador. Normalmente se realizó por teléfono, con el objetivo de acordar las fechas de visita. Durante la conversación, se comparte con el director o jefe de estudios la secuencia óptima de procedimiento de recogida de datos.

\section{Primer día:}

Entrevista con el director o jefe de estudios con el objetivo de contextualizar la investigación. Recoger datos de significación. Recoger información pertinente para realizar la observación.

El mismo día se procedía a la elaboración del croquis del patio y a fotografiar el espacio sin alumnos.

Segundo día:

Cuestionario al alumnado de cuarto. Recogida de información significativa sobre usos e intereses para el patio. Información sobre el contexto general de desarrollo del recreo.

Este mismo día se realizaba una observación focalizada en el patio con la presencia de los alumnos de cuarto. El objetivo de esta primera observación era recoger datos sobre las condiciones del patio, el ambiente, los usos, los grupos, las actividades, etc.

\section{Tercer día:}

Segunda observación focalizada. Seleccionar información sobre los usos de los alumnos de cuarto.

Una vez realizadas las tres visitas a los centros, la investigadora o el investigador traspasaba los datos recogidos:

1. Transcripción de la entrevista. Las entrevistas quedaron grabadas en formato de audio. Análisis cualitativo de los datos.

2. Descripción del patio, croquis e información fotográfica.

3. Descripción de las situaciones observadas.

4. Vaciado del cuestionario de encuesta en base de datos informatizada para ser analizada posteriormente con el paquete SPSS.

\section{Resultados}

Los resultados obtenidos se agrupan en tres grandes apartados de análisis.

\subsection{La construcción de una tipología de patios escolares: espacios, elementos e intervenciones}

A partir del análisis de varios indicadores, valoramos el estado de los patios, tanto desde el punto de vista físico como educativo. La información proviene 
tanto de las entrevistas con los equipos directivos como de las observaciones del patio, para cruzarlas y confrontarlas después con las respuestas obtenidas de los cuestionarios de encuesta.

Analizamos los aspectos físicos a partir de las dimensiones de los espacios, la variedad de espacios y superficies, la presencia o no de elementos de juego e infraestructuras. En cuanto a los aspectos docentes, nos fijamos, para valorar los patios, en las intervenciones educativas que se realizan, la presencia en el proyecto curricular, en el acceso a los juegos y juguetes y en la regulación que se hace de las actividades de juego en el patio.

Calidad de los espacios y los tiempos de patio. En los centros de la muestra, catorce de los treinta analizados tienen patios en «estado negativo». Han sido categorizados en estado negativo cuando, en una u otra dimensión (condiciones físicas y condiciones educativas), han obtenido esta valoración. Sólo hay dos centros (centro 1 y 21) que han obtenido esta valoración en ambas dimensiones, ambos de titularidad privada, uno de los cuales atiende a población de clase trabajadora y el otro atiende a población de clase media.

En el otro extremo, encontramos cinco centros con patios en "estado positivo» en alguno de los dos ejes. No hay ninguno que haya obtenido esta valoración positiva del patio en el ámbito físico y también en el ámbito educativo. En este caso, encontramos que de los cinco centros, tres son públicos y dos son privados (uno de ellos sin concertar). Todos ellos son centros grandes y atienden a población escolar de clase social alta (tres de cinco) y media (dos de cinco).

Finalmente, los once centros restantes tienen patios valorados en «estado aceptable».

Paralelamente a la línea de análisis de los dos apartados anteriores, abordamos a continuación cómo valora el alumnado estos tres tipos de centros en relación con las propuestas de cambios que hacen. Los resultados nos muestran

Gráfico 1. Distribución de propuestas de cambio y qué no les gusta a los alumnos del patio por valoración global de los patios

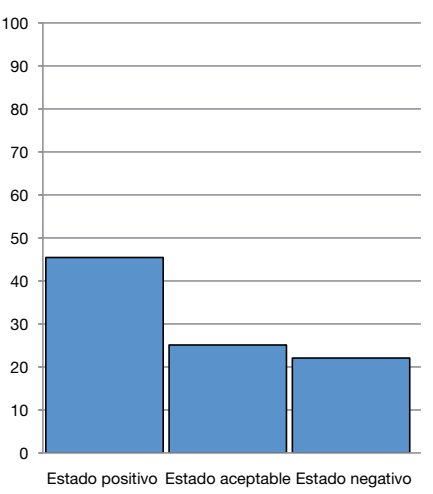

Fuente: elaboración propia.

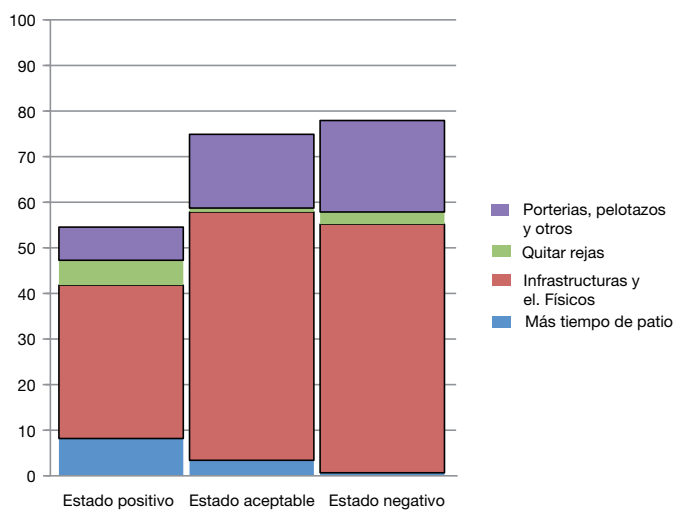


una correlación inversa entre los resultados de la valoración del estado del patio (física y educativa) y el nivel de satisfacción expresado por los alumnos.

- En general, el alumnado con patios en estado positivo formula una menor demanda de cambio y se muestra más satisfecho. También pide más tiempo de patio, posiblemente porque disfruta de este tiempo en mayor intensidad que los niños que tienen un patio en mal estado.

- El alumnado con patios en estado negativo formula una mayor demanda de cambio (sobre todo, de elementos físicos y de infraestructuras) y se muestra menos satisfecho (expresa más quejas, en especial para los pelotazos y las porterías) y decrece la demanda de tener más tiempo de recreo.

- En relación con las diferencias de respuesta por sexo, tanto las chicas como los chicos valoran sus patios de manera similar. No hay diferencias significativas en las demandas de cambio que hacen ellos y ellas, ni en la satisfacción manifestada sobre los patios. Tan sólo destacamos una pequeña diferencia por parte de los chicos que están en centros con patios valorados en estado negativo, ya que manifiestan una mayor demanda de cambios en las infraestructuras y en los elementos de juego que sus compañeras. Como decíamos en el apartado de análisis de las condiciones educativas, parecería que ellos tienen más claras las demandas de cambio para mejorar el espacio que ellas en el mismo tipo de patio, en este caso, valorado en estado negativo. Para el resto de valoraciones y demandas de cambio, chicos y chicas siguen de manera casi idéntica las tendencias señaladas en los puntos anteriores.

Finalmente, cabe señalar que el primer eje de análisis, las condiciones físicas del patio, ha resultado más significativo a la hora de establecer diferencias de valoración del alumnado que el eje construido a partir de lo que hemos llamado «las condiciones educativas del patio». Este resultado está muy ligado al hecho de que la situación de intervenciones educativas sobre los patios es muy similar en todos los centros educativos: es muy pobre y nos discrimina muy poco sobre lo que ocurre en general en los centros educativos en su globalidad. Cabe decir que, en los centros en los que se produce algún tipo de intervención, los resultados difieren mucho de aquellos en que intervienen poco. En este sentido, pues, nos permite diferenciar muy bien los centros ubicados en los dos extremos.

\subsection{La reconstrucción del juego en el patio en horario lectivo}

En esta parte de los resultados, presentamos el análisis realizado sobre el patio escolar en horario lectivo, qué actividades se desarrollan durante el tiempo de recreo, a qué se juega, qué relaciones se establecen entre el alumnado, con quién se relacionan, con quién se juega y cuál es la valoración que hace el alumnado del estado del patio. Recogemos las valoraciones sobre el estado del patio y las posibilidades de cambio, analizamos los discursos sobre la utilidad del recreo, tanto por parte del alumnado como del profesorado, así como la 
valoración que el alumnado hace acerca del rol y la presencia del profesorado en los patios escolares.

Los resultados nos muestran que hay diferencias de género y de clase social muy evidentes en las actividades que se desarrollan en los patios, así como también se reproducen diferencias en las preferencias por ciertas actividades y las relaciones que se dan.

- El sexo del alumnado encuestado vuelve a destacar diferencias en los tipos de actividades realizadas. Así, se observa claramente que un $60 \%$ de los chicos dice que ha realizado actividades movidas por contraposición al $40 \%$ de las chicas, que han combinado actividades movidas y más bien movidas en más ocasiones que sus compañeros. En cuanto a las actividades más bien quietas, sobresalen las chicas (un 20\%) el doble que los chicos de nueve años. Gráfico 1. Distribución de propuestas de cambio y qué no les gusta a los alumnos del patio por valoración global de los patios

Nuestros resultados concuerdan con los obtenidos por otros estudios en los que se documentan los tipos de actividades realizadas por el alumnado, como los de Blatchford (2003) o Boyle et al. (2003).

El comportamiento sobre el tipo de actividades realizadas en los patios entre chicos y chicas es similar por clase social y por titularidad de los centros. Las observaciones realizadas y las respuestas del alumnado en el cuestionario confluyen en la misma distribución del espacio: la pista deportiva, presente

Gráfico 2. Tipo de actividades por sexo y tamaño de los centros
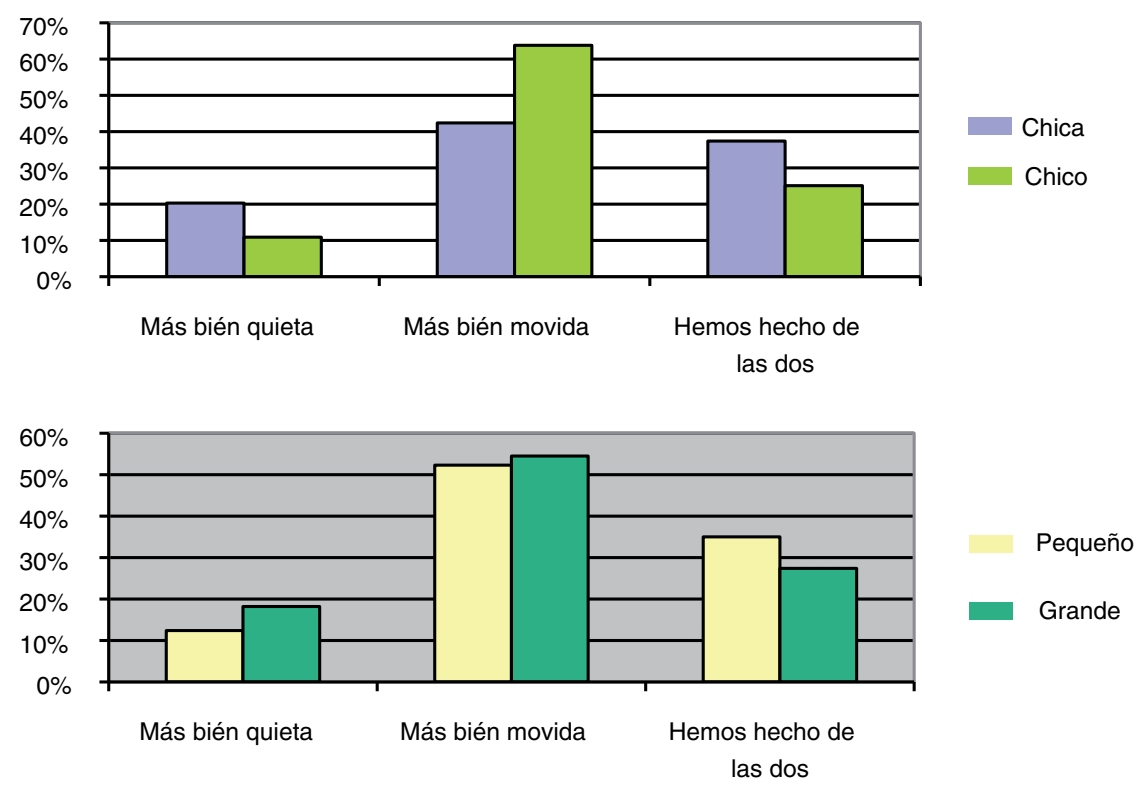

Fuente: elaboración propia a partir del vaciado de las encuestas. 
en los patios de todos los centros educativos de la muestra, acontece el lugar central del alumnado durante el tiempo de recreo (33\%), en segundo lugar, nos señalan un rincón $(29 \%)$ y, en tercer lugar, que se han movido por todo el patio $(27 \%)$.

Considerando el sexo del alumnado, en primer lugar, la mayoría de chicos se ubican en la pista, en segundo lugar, señalan todo el patio y, en tercer lugar, se ubican en un rincón. Este último espacio, el rincón, es significativamente el más importante para las chicas, en segundo lugar, se mueven por todo el patio y, en tercer lugar, se ubican en la pista. Otros espacios aparecen con porcentajes muy bajos, sobre todo por parte de las chicas: el banco, cerca de la puerta y en la fuente.

Las respuestas referidas al «rincón» nos están señalando un espacio que no es central, sino marginal. Estos chicos y chicas se ubican en lugares que se encuentran alejados de las puertas de entrada y salida, ni cerca de la fuente, ni en la pista deportiva. En estos espacios, los chicos y las chicas dicen que han realizado actividades más bien quietas en más de la mitad de los casos.

Estas descripciones se repiten a lo largo de las observaciones realizadas en todos los patios de la muestra:

No hay ningún tipo de ocupación del espacio según edad, puesto que todos los alumnos son de la misma clase. No obstante, sí que la hay por razón de sexo: la zona de la pista es utilizada exclusivamente por chicos que juegan al fútbol, y en una de las cestas de baloncesto situadas en la periferia hay un grupo de tres chicos jugando a baloncesto.

Las chicas tienen mayor presencia en la zona de porches, que, junto con unos cuantos chicos, aprovechan para jugar a la bola de fuego (matar).

Hay otros grupos diseminados: un grupo de chicos jugando con las cartas de Bola de Dragón, uno de chicas que ensayan una coreografía al ritmo de Wish you a merry Christmas y uno de mixto que va variando su actividad y se sitúa en la zona de la pista cerca de unas escaleras.

Observación centro 31

Esta otra descripción nos informa en el mismo sentido acerca de la distribución de actividades en los diferentes espacios:

Igual que en la anterior observación, en la pista se juega al fútbol (juego de normas), hay tres partidos simultáneos.

El resto de actividades se producen en la periferia de la pista, donde juegan a diferentes tipos de juegos: pilla-pilla, escondite, pintar, intercambio de pegatinas, cuentos, pulseras, carreras o cartas, etc.

Observación centro 17

- El alumnado se distribuye de maneras diferentes según el sexo y las actividades realizadas. Considerando el sexo del alumnado, la mayoría de chicos se ubican en la pista, después señalan todo el patio y, en tercer lugar, se ubican en un rincón. Este último espacio, el rincón, es significativamente el más 
importante para las chicas, en segundo lugar, se mueven por todo el patio y, en tercer lugar, se ubican en la pista. Otros espacios aparecen con porcentajes muy bajos, sobre todo para las chicas: el banco, cerca de la puerta y en la fuente. Las respuestas referidas al «rincón» nos están señalando un espacio que no es central sino marginal en los patios escolares. Estos chicos y chicas se ubican en espacios que se encuentran alejados de las puertas de entrada y salida, ni cerca de la fuente, ni en la pista deportiva. En estos espacios, los chicos y las chicas dicen que han realizado actividades más bien quietas en más de la mitad de los casos.

- Los resultados confirman que las actividades desarrolladas por grupos exclusivamente formados por chicas y por grupos mixtos son más variadas que las desarrolladas por grupos de sólo chicos. Los grupos mixtos tienen un número más grande de individuos que los monogenéricos, que son, en cambio, más frecuentes.

\subsection{La identificación del juego y los usos del tiempo fuera de la escuela}

En esta tercera parte, finalmente, analizamos las actividades desarrolladas por estos chicos y chicas fuera de la escuela, tanto las actividades organizadas como las informales, los tiempos invertidos, los tipos de actividades, las preferencias y alguna perspectiva de juego futuro preguntando qué juguetes no tienen y les gustaría tener.

Hemos analizado una serie de aspectos relacionados con el tiempo libre de los chicos y de las chicas, con las actividades que realizan fuera del horario lectivo mayoritariamente desarrollado fuera de la escuela. Son temas de capital importancia en cuanto a considerar el papel de la escuela, en el sentido de si esta tiene que complementar, y de qué manera lo debe hacer, las desigualdades sociales que se producen en el contexto comunitario en el cual se encuentra.

Hemos constatado las desigualdades de clase y de género en las preferencias $y$ en las actividades realizadas en el tiempo libre fuera del horario lectivo.

- La participación del alumnado en actividades extraescolares organizadas nos muestra que hay ciertas diferencias por clase social y tipo de actividad realizada, sobre todo en la superior práctica de la otra clase social en las actividades de cariz artístico (música y teatro) y en la participación asociativa (centros excursionistas y escultismo), mientras que la clase social baja y media que asiste a centros públicos practica más que la clase social alta actividades de cariz religioso.

- Sobre los lugares de juego, los datos nos muestran que, en los chicos de clase social baja que juegan más en la calle, los centros escolares están más cerca de los hogares y hacen los desplazamientos a pie entre casa y escuela. Esto es lo contrario de lo que pasa con los chicos y chicas de clase alta, ya que sus desplazamientos son en coche o autocar y sus lugares de juego fuera de la escuela están más ligados al hogar, el propio o el de amigos y amigas.

Como hemos dicho más arriba, todos los chicos y las chicas en conjunto señalan el hogar como el primer lugar de juego fuera de la escuela, a pesar de 
Gráfico 3. Actividades fuera de la escuela por clase social
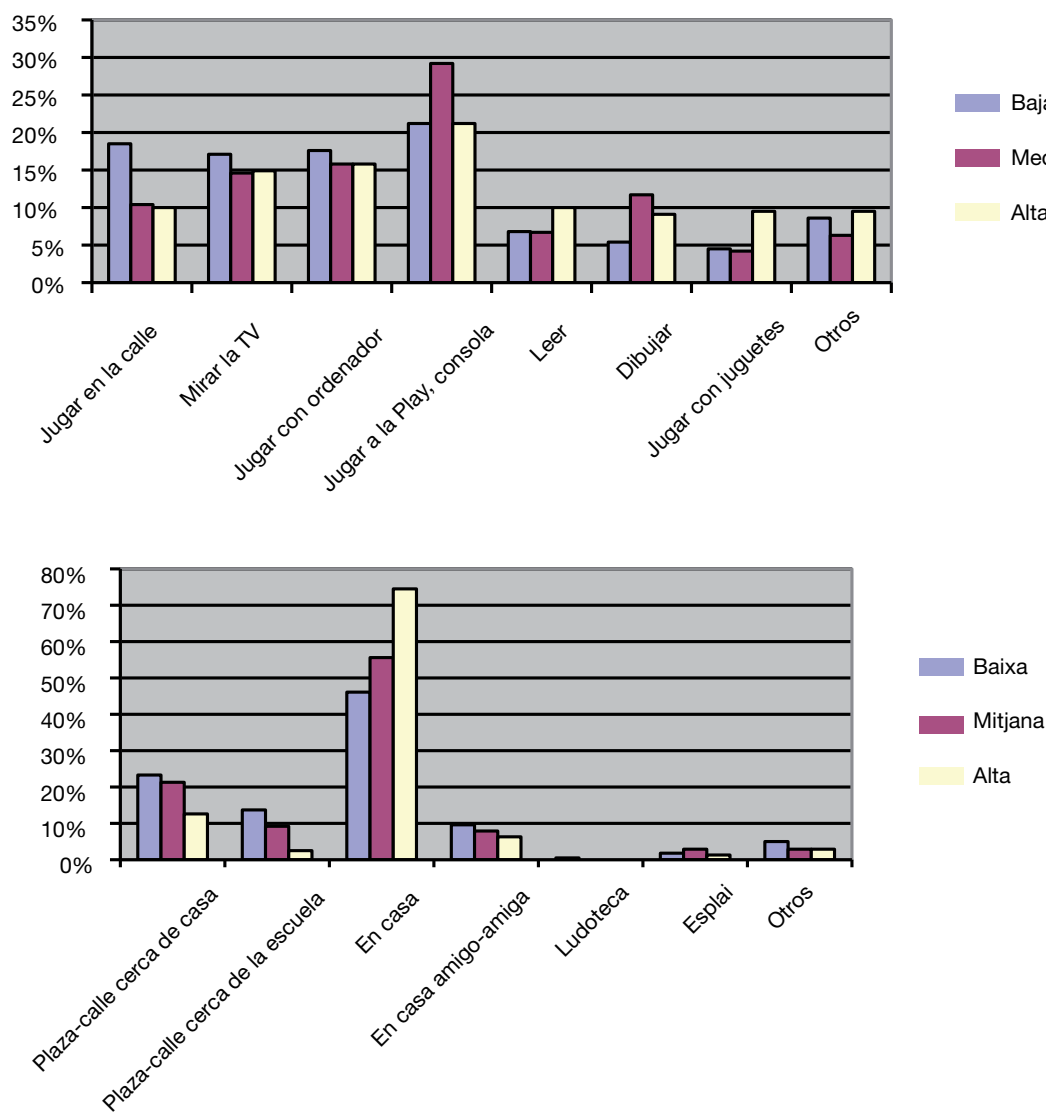

Fuente: elaboración propia a partir del vaciado de las encuestas.

que los chicos y las chicas de clase social alta mencionan el hogar significativamente más que los chicos y las chicas de clases media y baja (en este orden). Los chicos y las chicas de clase trabajadora señalan que juegan más a menudo en la calle que los chicos y las chicas de otras clases sociales, tanto en la calle cerca de casa como en la calle cerca de la escuela.

Los chicos y las chicas de clase media juegan más a menudo con consolas que los chicos y las chicas de otras clases sociales, y los chicos y las chicas de clase alta practican más las actividades de lectura y juegan más con juguetes que los chicos y las chicas de clase media y baja. La preferencia por otras actividades, como mirar la televisión o jugar al ordenador, se sitúa en niveles muy parecidos para los chicos y para las chicas de todas las clases sociales.

- Finalmente, en cuanto a las preferencias por juegos y juguetes, el estudio nos indica que, mientras que los chicos muestran más interés por las con- 
solas que acaban de ser puestas en el mercado esta temporada (Wii y PS3) que por los juegos electrónicos, las chicas muestran más interés por estos últimos. Ello nos podría indicar que el conocimiento de las especificidades del mercado del juego electrónico es más extenso en el ámbito de los chicos que en el de las chicas.

\section{Conclusiones e implicaciones}

A lo largo de las últimas décadas, nuestro país ha sufrido una serie de cambios de carácter sociodemográfico, sociocultural y educativo: envejecimiento de la población, viejos y nuevos flujos migratorios, alargamiento de la escolarización, penetración de nuevas tecnologías de la información y de la comunicación que se reflejan en dinámicas globales y locales. Todos estos cambios han contribuido a transformar los roles, de los hogares, de las formas de relación, en las conceptualizaciones de la infancia y de las estrategias y de los mecanismos utilizados en los procesos de enseñanza-aprendizaje. Uno de los lugares sobre el que recae la responsabilidad en nuestro contexto cultural es la escuela. Entendemos, pues, que se convierte en un espacio y en un tiempo muy importantes en la formación de nuestros niños en el ámbito de la educación formal. Es por estos motivos que hemos establecido como centro de nuestro análisis lo que sucede en el patio escolar, qué características tienen los espacios, qué conceptualizaciones se vehiculan a su alrededor y qué percepciones y qué discursos se construyen por parte de los agentes que desarrollan su actividad: profesorado y alumnado.

El diagnóstico del estado de los patios nos muestra una situación bastante decepcionante, puesto que, en general, el patio escolar no es considerado por la comunidad pedagógica como un espacio educativo de primer orden. Es un espacio que queda inscrito en el recinto escolar, pero fuera de las dependencias consideradas didácticas: las aulas.

- El alumnado de los centros docentes estudiados se adapta a las condiciones en las que se encuentra el espacio de juego del centro educativo al que asiste. Los chicos y las chicas hacen lo que les dejan hacer los lugares de los que disponen, siguiendo dos principios básicos: de agrupación y expansión. Hay que observar los espacios del patio y reflexionar en torno a su estado físico, replanteando la ubicación y observando los usos diferenciados de los elementos y los espacios por parte del alumnado. Los resultados de las observaciones nos permitirán actuar físicamente sobre los patios $\mathrm{y}$, aunque no debe ser el objetivo último de las intervenciones en los patios, será, muy probablemente, un buen comienzo para iniciar intervenciones más profundas y complejas que ayudarán a ubicar el patio como espacio educativo de los centros escolares.

El estudio nos muestra cómo en el patio se siguen reproduciendo desigualdades sociales y culturales que se manifiestan a través del acceso y la elección 
de los centros educativos y en las condiciones de escolarización del alumnado diverso: por sexo, por clase social y por origen sociocultural.

- No hay grandes diferencias en los discursos asociados al patio y qué significan dentro de los proyectos educativos de los centros escolares de la muestra, a pesar de su diversidad. En los proyectos educativos de los centros, nos cuentan que se recoge información sobre los patios, ya que se plasman los planes y la filosofía de fondo. Algunas entrevistas se refieren a lo que representan como espacio de acogida de las familias en las entradas y salidas y las fiestas que se celebran a lo largo del curso. Básicamente, en los demás documentos, planes anuales y reglamentos de régimen interno, se recoge la normativa del patio, se detallan los espacios, la vigilancia y las reglas a seguir en el recreo. Esta importancia otorgada al juego y al espacio de juego contrasta con las prácticas observadas.

- La gran mayoría de los centros estudiados separa los espacios y los horarios de recreo del alumnado por edades. Nos encontramos ratos de juego que imposibilitan el juego entre chicos y chicas de diferentes edades y, por tanto, la transmisión de contenidos entre iguales. Lo que ocurre más a menudo es que se encuentren compartiendo un mismo espacio chicos y chicas de dos niveles consecutivos, de modo que la interacción entre iguales, que podemos encontrar en otras agrupaciones fuera del ámbito de la educación formal, queda muy limitada.

- La clase social asignada a los centros revela comportamientos de agrupación en el patio muy diferenciados entre clase social baja y media, por un lado, y clase social alta, por otro.

Las intervenciones y las estrategias desarrolladas por los equipos docentes en los patios de los centros educativos son también variadas y, a menudo, se obtienen respuestas no deseadas pero poco tomadas en cuenta, en tanto que en la mayoría de los casos no generan conflictos explícitos que pidan la intervención de los adultos.

- Constatamos que se produce una clara invisibilización de las actividades de las chicas en los patios, puesto que quedan excluidas en los márgenes, mientras que los espacios centrales quedan ocupados por la pista de juego deportivo y el fútbol, actividad mayoritariamente realizada por chicos. Cuando la pelota desaparece, las actividades cambian, se diversifican, igual que los tipos de relaciones que se establecen en las actividades en los patios.

- La presencia de profesorado en los patios es muy diversa según la titularidad y la clase social atendida en los centros educativos: se establece una relación directa entre clase social, la titularidad y el tamaño de los centros educativos y el número de profesorado que vigila los patios. Los centros más grandes, que atienden a clase alta y de titularidad privada tienen una mayor presencia de profesorado en los patios. De las valoraciones hechas por los chicos y las chicas de estos centros se desprende que donde hay 
más presencia de profesorado en los patios se percibe que su actitud es más activa, pero también ligeramente más punitiva, que en los centros donde hay una menor presencia de profesorado en el patio. Los chicos piden más que las chicas que el profesorado deje de regañar y castigar, mientras que las chicas piden más que los chicos que el profesorado juegue más.

Estas conclusiones nos llevan a identificar tres grandes núcleos de discusión a partir de los cuales emergen unas implicaciones claras para la intervención, que exponemos seguidamente.

\subsection{Persistencia de las desigualdades de clase y género en los patios escolares}

El estudio del estado de los patios escolares nos ha mostrado unos resultados que esperábamos y otros que nos han sorprendido. Esperábamos que los centros a los que asiste alumnado de familias de clase social alta estuvieran en mejores condiciones que los centros que atienden alumnado procedente de las clases sociales media y baja, y los resultados así nos lo muestran y contribuyen a reforzar la idea de prácticas de distinción de las familias según clase social en la elección de centros educativos para sus hijos e hijas: las mejores condiciones de los centros seleccionados por las familias acomodadas incluyen, también, las instalaciones y los patios. El acceso de las clases sociales altas en los centros en mejores condiciones se produce tanto en centros de titularidad pública como privada.

La doble red en la titularidad de los centros también queda evidenciada al analizar los patios, pero la cuestión es aquí más reveladora: las estrategias de distinción de las clases sociales trabajadoras que seleccionan escuelas de titularidad privada priorizan otros aspectos que no pasan por el estado de las infraestructuras escolares ni, concretamente, de los patios escolares. Los criterios de selección de los centros por parte de las familias pasa por otros criterios, seguramente por discursos elaborados desde los centros educativos vinculados a la calidad de otros espacios escolares, que nos obligan a cuestionarnos sobre la consideración y la importancia que el profesorado y las familias otorgan al patio escolar como espacio educativo. Trataremos más a fondo la importancia que el profesorado otorga en el punto siguiente.

Si bien ya hemos señalado que las desigualdades se manifiestan en el acceso diferenciado a los centros educativos, las condiciones de escolarización también reflejan desigualdades de clase. Las condiciones de escolarización del alumnado pasan por focalizar nuestra atención sobre las intervenciones educativas que se realizan en los patios, y en general las intervenciones son muy pocas en todos los centros educativos. De hecho, cuando se producen, hacen que los centros se ubiquen en extremos opuestos y distanciados, igual que queda ubicado el alumnado atendido en estos centros. Cuando existen intervenciones educativas en los centros, es decir, proyectos educativos vinculados a los patios o áreas curriculares que desarrollan algunas de sus actividades, se producen mejoras en las condiciones de escolarización, pero observamos que esto está pasando 
exclusivamente en los centros que atienden alumnado de clases sociales altas y no en los centros privados que atienden alumnado de clases sociales bajas. Esto redunda en la idea de que no se está garantizando el principio de ofrecer la misma calidad en la enseñanza entre centros financiados con fondos públicos, sobre todo cuando se está atendiendo al alumnado con menos recursos socioeconómicos y menos apoyo educativo fuera del sistema, con menos acceso, por ejemplo, a actividades organizadas de carácter académico o artístico.

Los usos del tiempo fuera del horario lectivo muestran y refuerzan desigualdades de género y de clase social, tanto en las actividades realizadas fuera de la escuela, en los juegos, en los demás lugares de juego como en las actividades extraescolares organizadas que realizan los chicos y las chicas. Así, si la escuela debe responder a las desigualdades sociales del entorno, es necesario que se replantee cuál debe ser el rol a desarrollar, si es necesario contrarrestar el peso de estas prácticas y de estos desequilibrios fuera de la escuela y replantear qué pasa en los patios con el alumnado diverso por género, clase social y etnia. En este sentido, el patio se muestra claramente como un óptimo recurso potencial totalmente desaprovechado.

El patio escolar es el gran espacio de fomento de las relaciones entre el alumnado y de los modelos de estas relaciones. Si bien ya hemos comentado que existen prácticas de acceso al sistema educativo que manifiestan las desigualdades de clase social, con los resultados del estudio, también hemos confirmado, y aunque sea de forma indirecta, que se fomentan las desigualdades de género. Por un lado, se repiten estrategias de selección de centros de titularidad privada por parte de familias de clase alta en función de la segregación de alumnado por sexo que estos centros realizan, lo que vuelve a romper con el principio de ofrecer la misma calidad en la enseñanza de los centros financiados con fondos públicos, a la vez que también lo hacen con el principio de coeducación.

Por otro lado, los resultados del estudio nos descubren prácticas del alumnado y estrategias desarrolladas por los centros que nos obligan a cuestionarnos sobre lo que significa el principio de coeducación y qué incidencia tiene en los centros escolares. Otros referentes teóricos ya nos habían mostrado las preferencias y las prácticas diferenciadas por sexo en el patio escolar, y este estudio también las refleja. Constatamos que se produce una clara invisibilización de las actividades de las chicas en los patios, puesto que quedan excluidas en los márgenes. Este fenómeno llega a puntos más álgidos cuando documentamos algunos grupos de chicas de origen extranjero que quedan también segregadas del resto de compañeras, mientras que sus compañeros de origen extranjero se incorporan a las actividades del grupo de chicos a través del fútbol. Las diferencias de género tienen mucho más peso que otras en el análisis de las actividades realizadas en el patio, pero no significa que se tenga en cuenta en las intervenciones que se realizan por parte de los centros.

Es lamentable observar la falta de planteamientos coeducativos reales y la falta de objetivos educativos para la igualdad en las relaciones de género, tanto en la organización de los espacios de los patios, como en la regulación de las 
actividades que se realizan. Entendemos que no se garantiza la presencia ni el reconocimiento de saberes y de prácticas de las mujeres, de las chicas o de las niñas en los currículos explícitos y ocultos en los patios escolares de los centros educativos, al contrario, quedan invisibilizadas y sin ninguna intervención por parte de los adultos.

\subsection{Constatación de contradicciones entre discursos y prácticas educativas del profesorado en relación con los patios escolares}

Las estrategias de intervención del profesorado en los patios escolares son pocas y obtienen, en algunos casos, resultados no deseados. La regulación de los usos de la pista del patio o la distribución horaria por niveles educativos del patio, por un lado, pueden facilitar la convivencia en los patios, porque disminuye la presencia de chicos y chicas en un mismo espacio, mientras que, por otro lado, contribuyen al empobrecimiento de las actividades de juego y lúdicas en los espacios de patio escolar, ya que las posibilidades de intercambio de juegos y actividades entre chicos y chicas de diferentes edades quedan anuladas cuando sabemos que, en otros ámbitos fuera de la escuela, estas relaciones entre edades facilitan los procesos de transmisión sociocultural y de valores que podrían ser ámbitos de aplicación de muchos de los valores que contienen los proyectos educativos defendidos por los centros.

Pero los equipos educativos de los centros desarrollan otras estrategias en el patio, con más o menos conciencia, según la población escolar que están atendiendo: hay una sobrerrepresentación de patios en peor estado (menos acceso a juegos, menos variedad en los espacios de juego, más prohibiciones, etc.) en centros de titularidad privada que atienden a población de clase social trabajadora, lo que nos hace cuestionarnos sobre las incoherencias entre los discursos vinculados al juego y al patio y las actitudes que el profesorado desarrolla.

En este sentido, no hay coherencia entre la importancia otorgada por el profesorado en sus discursos sobre los proyectos educativos de los centros, sus idearios cuando se refieren al juego como herramienta educativa y como herramienta de transmisión cultural, y sus prácticas. Hay que explorar los posibles conflictos generados por la falta de reconocimiento en el horario laboral del profesorado de suficientes espacios de descanso y reflexión. Así, el patio acaba por convertirse en el mal menor que hay que sufrir algún día a la semana para disponer los demás días de un rato de descanso. Aunque reconocemos y apoyamos esta necesidad de regulación, es necesario un replanteamiento de fondo que haga ocupar, al patio y al recreo, el lugar que le corresponde en la educación obligatoria. Una opción posible sería la de pensar en un perfil de personal cualificado y específico para los ratos de recreo, tanto dentro como fuera del horario lectivo, pero intuimos las problemáticas que podrían surgir similares a las de otros perfiles específicos presentes en el espacio escolar, sobre los que recae cualquier responsabilidad de los temas que surgen cuando tienen una mínima vinculación con su figura. Preferimos pensar en un perfil transversal que sea compartido y aprovechado por el conjunto del profesorado 
para aumentar las probabilidades de que el patio sea considerado un espacio educativo más en los centros escolares en los que se llevan a cabo objetivos educativos de peso.

Las intervenciones del profesorado en el patio se vinculan mayoritariamente a situaciones de conflicto y el conflicto es visto solo en los casos más explícitos: en forma de reclamaciones del alumnado, en forma de peleas o en forma de accidentes, otras situaciones no son consideradas como conflicto, ya que no necesitan, explícitamente, de la atención de los adultos, como en el caso de que las chicas ocupen permanentemente y mayoritariamente lugares y espacios secundarios en el espacio de juego de la escuela, situación que no es vista en términos de conflicto mientras no genere quejas ni interpelaciones del alumnado hacia el profesorado para intervenir y buscar soluciones. Podríamos pensar en preferencias para estos espacios por el tipo de actividades y relaciones que suelen desarrollar más las niñas y las chicas en estas edades, pero no podemos ignorar el volumen de quejas mayor que estas expresan - y también algunos niños y chicos- en relación con la vulnerabilidad en torno a los espacios centrales ocupados por los chicos y sus actividades de carácter hegemónico.

Si la lectura de conflicto se limita a los casos más extremos, obviamente, deben tener algún tipo de respuesta, porque eso significa que hay una serie de situaciones no deseadas que pasan desapercibidas, y muchas veces estas situaciones son las que afectan, mayoritariamente, a las chicas y al alumnado de minorías y, en algunos casos, a algunos chicos que no participan de las actividades mayoritarias en los patios, como hemos dicho más arriba. En el mismo sentido, el estudio ha hecho emerger las visiones diferentes que tienen chicos y chicas sobre el papel desarrollado por el profesorado en el patio, más o menos punitivo o de vigilancia que participativo en un sentido propositivo.

Hay dos vertientes que nos permiten reflexionar sobre este núcleo temático. Por un lado, podemos cuestionarnos sobre qué implicación tiene el constante bombardeo de noticias en torno a la violencia escolar en los medios de comunicación y como provoca cierta ceguera hacia estas situaciones o, dicho de otro modo, como el resultado es una sobrefijación en las situaciones más extremas. Por otro lado, nos lleva a cuestionarnos sobre cuál es el autoconcepto del propio profesorado y sobre cuáles deben ser sus tareas en la escuela, específicamente en el patio, y cuál es el papel social que le es otorgado. Las desconfianzas existentes entre familia y escuela podrían estar contribuyendo a la desafección y paralización del profesorado, en el sentido que actuaría «apagando fuegos», actuando sobre lo más evidente y urgente, dejando de lado actuaciones más comprometidas y profundas por simple cansancio de una situación sobrevenida o sobredimensionada en los últimos años.

Hay que tener en cuenta los efectos de las tensiones y las contradicciones de los procesos de control de las actividades en los patios escolares sobre las experiencias de chicos y chicas de diferentes clases sociales y de orígenes culturales diversos y los resultados que pueden tener en la adquisición de contenidos propios del currículo transversal y/u oculto, así como en las experiencias de relación con los iguales dentro y fuera de la escuela. En este mismo sentido, resulta 
absolutamente necesario reflexionar sobre la consideración del patio como un espacio susceptible de ser empleado y de las potencialidades que ofrece su uso en las diversas áreas curriculares, si bien son pocas las áreas curriculares que lo consideran para desarrollar alguna actividad: las hay que no lo hacen nunca, por ello, el principio pedagógico de la necesidad de que los aprendizajes sean significativos queda en entredicho ante este hecho.

Es necesario un replanteamiento de las prácticas educativas cotidianas del profesorado sobre los patios, observación cuidadosa de las dinámicas relacionales entre el alumnado que se producen en los patios para convertirlas en inclusivas desde la vertiente más crítica y transformadora, si es que estamos de acuerdo en que la escuela debe cumplir con estas características. Probablemente esto tenga que pasar por cuestionarnos sobre cuál es la formación básica y permanente que recibe el profesorado y por potenciar la difusión de buenas prácticas y experiencias positivas en los patios escolares.

\subsection{Identificación de la falacia del juego libre en los planteamientos educativos de los centros}

Uno de los discursos más repetidos en las entrevistas realizadas a los equipos directivos de los centros educativos se basa en interpretar y entender el juego en el patio como rato de juego libre, rato de descompresión, en el sentido de justificar, así, que no haya ningún tipo de intervención de los adultos, ya que esto significaría orientar o dirigir las actividades que realizan en el patio y permitir que el alumnado interactuara como quisiera. Pero constatamos que este juego libre no es tal. Entendemos que el juego libre no existe si tenemos en cuenta que siempre hay algún tipo de restricción, más o menos explícita, evidente y susceptible de ser modificada en el juego en el patio. Siempre hay una regulación de las actividades permitidas y prohibidas en los patios. Puede ser un listado verbalizado, escrito, trabajado en las aulas o no y puede estar supeditado a unas características físicas, presencia de elementos de juego, acceso a infraestructuras que construyen las actividades que se pueden realizar. Asumiendo, pues, que no hay tal libertad en el juego desde el punto de vista empírico, las opciones de intervención en los patios escolares pueden dirigirse en dos direcciones:

- Modificando esta situación de partida interviniendo en los aspectos físicos del patio y en la regulación de las actividades que allí se pueden o no realizar.

- Si entendemos que jugar es una actividad que puede y debe ser enseñada y aprendida, estimulando la capacidad de juego promocionando formas de jugar, juegos y juguetes, experimentando nuevas formas de relacionarse, de ampliar las actividades de los patios incorporando los bagajes lúdicos familiares, populares, multiculturales y tradicionales dentro de la escuela.

Esta segunda opción más propositiva nos lleva al debate sobre la necesidad de incorporar los juegos electrónicos en las escuelas, en general, y en los patios 
de las escuelas, en particular. Aunque el estudio nos ha mostrado la distancia entre las actividades lúdicas preferidas por los chicos y las chicas y las realizadas dentro de la escuela, queda pendiente plantearnos sobre cuál tiene que ser la respuesta de la escuela ante las nuevas tecnologías, específicamente teniendo en cuenta la gran irrupción que los juegos electrónicos están teniendo en el tiempo libre de los niños. La línea de reflexión sobre la oportunidad y el potencial de uso de los juegos electrónicos en el ámbito educativo nos permite afrontar otras problemáticas asociadas a la educación.

La incorporación de los juegos electrónicos en el ámbito educativo podría dar respuesta a otro gran problema relacionado con el acceso a las nuevas tecnologías por sexos y orígenes socioculturales, lo que se conoce como «la brecha digital». Algunas actuaciones en patios de centros escolares favoreciendo el acceso a aulas de informática o trasladándolas a los patios podrían contribuir a acortar distancias entre los diferentes niveles.

En definitiva, si lo que buscamos es la excelencia educativa para todo el mundo, luchar contra la persistencia de varias formas de desigualdades manifestadas en el espacio escolar - perfectamente reflejadas en los patios, como ha mostrado este estudio- y asegurar la inclusión de todos los chicos y las chicas en edad escolar, de las familias, de los docentes y del entorno, hay que reconsiderar el patio escolar como un espacio educativo, y esto significa mirarlo y observarlo, para ver qué sucede y para intervenir desde principios y objetivos educativos.

\section{Referencias bibliográficas}

Agramunt, M.; Prats, B. y Vidal, V. (2004). «El patio, espacio educativo». Cuadernos de Pedagogía, 332, 28-30.

BADIA, R. (2003). «Viaje virtual al mundo de los juegos». Tándem: Didáctica de la Educación Física, 10, 74-82.

BANTUlÀ, J. (2003). «La recuperación de la antesala del juego». Tándem: Didáctica de la Educación Física, 10, 59-73.

BARBOUR, A.C. (1999). "The impact of playground design on the play behaviors of children with differing levels of physical competence». Early Childhood Research Quarterly, 14 (1), 75-98.

BAUTISTA, V. (2006). "Jocs de tauler». Educació Social: Revista d'Intervenció Socioeducativa, 33, 113-120.

BernabÉ, J. (2006). «¿A qué jugabas, abuela?». Cuadernos de Pedagogía, 357, 32-34.

BIXLER, R.D. et al. (2002). «Environmental Socialization: Quantitative Tests of the Childhood Play Hypothesis». Environment and Behavior, 34 (6), 795-818.

BlATCHFORD, P. et al. (2003). "The social context of school playground games: Sex and ethnic differences, and changes over time after entry to junior school». British Journal of Developmental Psychology, 21, 481-505.

Bonal, X. y TomÉ, A. (1996). «Metodologias y recursos de intervención». Cuadernos de Pedagogía, 245, 56-69.

BoyLe, D. et al. (2003). «Gender at Play: Fourth-Grade Girls and Boys on the Playground». American Behavioural Scientist 2003, 46 (10), 1326-1345.

BreLl, M. (2006). «Jocs de rol». Educació Social: Revista d'Intervenció Socioeducativa, $33,103-112$. 
CALlís, J. (2003). «El joc i la formació matemàtica a primària: Jocs per apendre i fer pensar». Perspectiva Escolar, 273, 23-34.

CARBOnell, A. y otros (1996). "El juego en el parvulario: instrumento para el desarrollo y el aprendizaje». Aula de Innovación Educativa, 5 (52/53), 5-12.

Carrasco, S.; Ponferrada, M.; Villa, R. y Miró, M. (2006). Convivència i confrontació entre iguals als centres educatius. Barcelona: CIIMU. Monogràfics, 8.

Castro, M.J. (2008). "La escuela, una perspectiva desde el juego». Aula de Innovación Educativa, 170, 67-69.

Chivite, J. (2002). "Experiència escolar "Els ocells del pati”». Perspectiva Escolar, 268, 54-64.

Colla, B. (2005). «Playful Kids, Strong Bones». Pediatrics for Parents, 21 (9), 7.

Colwell, M. y Lindsey, E. (2005). «Preschool Children's Pretend and Physical Play and Sex of Play Partner: Connections to Peer Competence». Sex Roles, 52 (7-8), 497-509.

Conde, O. y Pinzolas, J.A. (2005). «Los patios de recreo: espacios para la biodiversidad». Aula, 140, marzo.

CuEnCA, J.M. (2001). «Los juegos informáticos de simulación en la enseñanza y el aprendizaje de las ciencias sociales». Iber: Didáctica de las Ciencias Sociales, Geografía e Historia, 30, 69-82.

Deulofeu, J. (2003). «El joc en l'ensenyament de les matemàtiques: diversitat d'opcions i recursos». Perspectiva Escolar, 273, 5-13.

EDO, M. (2003). «Jocs només per calcular? Amb els petits es pot anar més enllà?». Perspectiva Escolar, 273, 14-22.

Gagnon, S.G. y NAGLE, R.J. (2004). «Relationships Between Peer Interactive Play and Social Competence in At-Risk Preschool Children». Psychology in the Schools, 41, 173-189.

GarveY, C. (1978). El juego infantil. Madrid: Morata. Serie Bruner.

Giuliano, T.A. y Popp, K.E. (2000). «Footballs Versus Barbies: Childhood Play Activities as Predictors of Sport Participation by Women». Sex Roles, 42 (3-4), 159-181.

Gómez Mayorga, C. (1998). "El patio dentro del aula». Cuadernos de Pedagogía, 266, 19-21.

GonZÁlez Gallego, I. (2001). «El juego en la historia social y el juego en el aprendizaje de las ciencias sociales». Iber: Didáctica de las Ciencias Sociales, Geografía e Historia, 30, 7-22.

GRUGEON, E. (2005). "Listening to learning outside the classroom: Student teachers study playground literacies». Literacy, 39 (1), 3-9.

Guitart, R. (1996). "¿A qué jugamos? Los valores en el juego". Aula de Innovación Educativa, 5 (52/53), 25-29.

HERNÁNDEZ, F.X. (2001). «Los juegos de simulación y la didáctica de la historia». Iber: Didáctica de las Ciencias Sociales, Geografía e Historia, 30, 23-36.

HOWARD, A.W. et al. (2005). "The effect of safer play equipment on playground injury rates among school children». Canadian Medical Association Journal, 172 (11), 1443-1446.

Hudson, S.D. et al. (2005). «How SAFE Are School and Park Playgrounds?: A Progress Report». Journal of Physical Education, Recreation \& Dance, 76 (1), 16-20, 28.

IgOA, J. y AldabAldetreKU, O. (2006). «Experiències d'Intered Euskal Herria en relació amb la potencialitat del joc cooperatiu». Educació Social: Revista d'Intervenció Socioeducativa, 33, 91-102. 
Lavega, P. (2003). «El juego en la educación física: En busca de una Estrella Polar». Tándem: Didáctica de la Educación Física, 10, 7-20.

- (2006). "El joc i la tradició en l'educació de valors». Educació Social: Revista d'Intervenció Socioeducativa, 33, 53-71.

LEFF, S.S. et al. (2004). «Using participatory research to develop a playground-based prevention program». Journal of School Psychology, 42 (1), 3-21.

López Ros, V. y EBerle, T. (2003). «Utilizar los juegos para aprender a resolver conflictos». Tándem: Didáctica de la Educación Física, 10, 41-50.

Marín, I. (1996). "El juego en la educación primaria». Aula de Innovación Educativa, $5(52 / 53), 19-24$.

- (2006). «Les joguines. Ben cansades se'n van doncs a descansar!». Educació Social: Revista d'Intervenció Socioeducativa, 33, 28-52.

Marín, I. (dir.); Molins-PueYo, C. et al. (2010). Els patis de les escoles: espais d'oportunitats educatives [en línea]. Barcelona: Fundació Jaume Bofill. Informes Breus, 31. <http://www.fbofill.cat/intra/fbofill/documents/publicacions/525.pdf>.

MARRÓN, M.J. (2001). «El juego como estrategia didáctica para favorecer el aprendizaje de la geografía». Iber: Didáctica de las Ciencias Sociales, Geografía e Historia, 30, 55-68.

MARTIN, C.L. et al. (1999). "Social cognition on the playground: Children's beliefs about playing with girls versus boys and their relations to sex segregated play». Journal of Social and Personal Relationships, 16 (6), 751-771.

MARTínez MuÑoz, L.F. et al. (2003). «Un recreo escolar para una motricidad en juego». Tándem: Didáctica de la Educación Física, 14, 83-92.

MERINO, S. y CONTÍn, S.A. (2001). "Jugar y simular para comprender nuestra diversidad: un desafío para las aulas de secundaria». Iber: Didáctica de las Ciencias Sociales, Geografia e Historia, 30, 83-91.

Meyer, H.A. et al. (2004). "Teachers reasoning about school fights, contexts, and gender: an expanded cognitive developmental domain approach». Aggression and Violent Behavior, 9 (1), 45-74.

Meyerhoff, M.K. (2001). «Perspectives on parenting: Having fun and learning». Pediatrics for Parents, 19 (1), 8-9.

Molins-Pueyo, C. (1998). Aproximació a l'estudi del joc com a aprenentatge sociocultural. Trabajo de investigación de máster dirigido por la Dra. Silvia Carrasco. Barcelona: UAB.

- (2005). «Ventajas, dificultades y límites de la etnografía escolar: Estudio del aprendizaje sociocultural a través del juego». Actas de la I Reunión Cientifica Internacional sobre Etnografia y Educación. Talavera de la Reina, 12 a 14 de julio de 2004. Valencia: Germania.

- (2006a). "Cultural Change and Play: on Schools' Misunderstanding of teenage Knowledge». PlayRights Journal: An International Journal of the Theory and Practice of Play [en línea], 27 (1), 4-11. International Play Association «Promoting the Child's Right to Play». <http://www.ipaworld.org/Journals/PlayRights_ v27n1_2006.pdf>.

- (2006) $)$. Use and Misuse of Information and Communication Technologies in Education in Spain: Limits to Change and Cultural Production». Electronic Magazine of Multicultural Education [en línea], 8 (1). <http://www.eastern.edu/ publications/emme/2006spring/molins-pueyo.pdf>.

Monterde, M. (2006). «Cuántos metros cuadrados mide el patio?». Cuadernos de Pedagogía, 355, 63-67. 
ÖFELE, M.R. (2003). «Papel social de los juegos tradicionales. Proyecciones pedagógicas». Tándem: Didáctica de la Educación Física, 10, 21-30.

Ortega, R. y LozAnO, T. (1996). «Espacios de juego y desarrollo de la autonomía y la identidad en la educación infantil». Aula de Innovación Educativa, 5 (52/53), 13-17.

OrTí, J. (2003). «Los juegos tradicionales: Aplicación en el área de la educación física en el sistema educativo actual». Tándem: Didáctica de la Educación Física, 10, 31-40.

PENÓN, S. (2006). «El joc i la joguina i l'infant hospitalitzat». Educació Social: Revista d'Intervenció Socioeducativa, 33, 121-130.

- (2006). «Les ludoteques». Educació Social: Revista d'Intervenció Socioeducativa, 33, $82-90$.

Pereira, B.O. et al. (2002). «Reinventar los espacios de recreo para prevenir la violencia escolar». Cultura y Educación, 14 (3), 297-311.

PiñeIro, M.R. (2001). "Los juegos de simulación para el conocimiento del medio». Iber: Didáctica de las Ciencias Sociales, Geografia e Historia, 30, 46-54.

PRAT, J. (1998). Aproximació al joc infantil al Vallès Occidental de 1900 a 1940. Trabajo de investigación de máster dirigido por la Dra. Silvia Carrasco. Barcelona: UAB.

Rambla, X. y Rovira, M. (1999). "El sexisme al pati de joc». Perspectiva i Diversitat. Suplement de Perspectiva Escolar, 5, 1-15.

Ripoll, O. (2006). «El joc com a eina educativa». Educació Social: Revista d'Intervenció Socioeducativa, 33, 11-27.

Rodríguez SuÁreZ, S. (2003). "Juegos y juguetes olvidados». Cuadernos de Pedagogía, 331, 24-26.

Salaverría, M.P. et al. (2003). "Grandes pintores en el recreo». Cuadernos de Pedagogía, 320, 20-21.

SERRAT, N. y SANTACANA, J. (2001). "Una reflexión sobre conceptos históricos aprendidos a través del juego». Iber: Didáctica de las Ciencias Sociales, Geografía e Historia, 30, 37-45.

STRATTON, G. (2000). «Promoting children's physical activity in primary school: An intervention study using playground markings». Ergonomics, 43 (10), 1538-1546.

Swain, J. (2000). «The Money's Good, The Fame’s Good, The Girls are Good: The role of playground football in the construction of young boys' masculinity in a junior school». British Journal of Sociology of Education, 21 (1), 95-109.

Tomé, A. y RuIZ, R.A. (1996). «El espacio de juego: escenario de relaciones de poder». Aula de Innovación Educativa, 5 (52/53), 37-41.

TRIGUeros, C. (2000). Nuevos significados del juego tradicional en el desarrollo curricular de la educación física en centros de educación primaria de Granada. Tesis doctoral. Texto inédito. Universidad de Granada.

VidAL, J. (2003). «Juguemos todos juntos!». Tándem: Didáctica de la Educación Física, $10,52-58$.

VINYALS, X. (2006). «El joc i les persones amb discapacitats». Educació Social: Revista d'Intervenció Socioeducativa, 33, 72-81.

VIRGILI, E. (2001). «El joc. Juguem i aprenem». Guix, 274, 43-45.

VV.AA. (2003). «El placer de jugar. El placer de educar». Tándem: Didáctica de la Educación Física, 10, 5-6.

VV.AA. (2007). Recuperem els jardins escolars. Barcelona. Octaedro.

VV.AA. (2008). Temps de les famílies: Anàlisi sociològica dels usos dels temps dins de les llars catalanes a partir de les dades del Panel de Famílies i Infancia. Barcelona: Generalitat de Catalunya. Departament d'Acció Social i Ciutadania. Secretaria de Polítiques Familiars i Drets de Ciutadania. 